\title{
Correlação linear entre componentes da produção e produtividade do arroz de terras altas em sistema plantio direto ${ }^{1}$
}

\section{Linear correlation between components production and yield of rice upland in no-tillage}

\author{
Flávio Carlos Dalchiavon ${ }^{2 *}$; Morel de Passos e Carvalho ${ }^{3}$; Admar Junior Coletti ${ }^{4}$; \\ Gustavo Caione ${ }^{4}$; Amilton Ferreira da Silva ${ }^{4}$; Marcelo Andreotti ${ }^{3}$
}

Resumo

\begin{abstract}
O arroz é uma das principais fontes de alimentação da humanidade. Durante o ano agrícola 2009/2010, no município de Selvíria (MS), no Cerrado Brasileiro, foi instalado um experimento com arroz de terras altas em um Latossolo Vermelho distroférrico sob sistema plantio direto, irrigado por pivô central, com o objetivo de selecionar os melhores componentes da produção para explicar a variabilidade da produtividade do arroz de terras altas irrigado. Foi instalada a malha geoestatística, para a coleta de dados, com 120 pontos amostrais, numa área de 3,0 ha e declive homogêneo de $0,055 \mathrm{~m} \mathrm{~m}^{-1}$. A produtividade média de grãos de arroz foi de $5980 \mathrm{~kg} \mathrm{ha}^{-1}$. Para as regressões lineares simples, o número de espiguetas granadas por panícula apresentou a melhor correlação potencial direta com a produtividade de grãos de arroz, dada por: $\mathrm{PGO}=115,5 . \mathrm{NEG}^{0,770}$. Entretanto, para as regressões lineares múltiplas, a equação $\mathrm{PGO}=2754,30-411,55 . \mathrm{NEG}-461,07 . \mathrm{NEC}+436,59 . \mathrm{NET}$ foi a que melhor se apresentou para estimar a produtividade de grãos de arroz. No entanto, espacialmente, não foi possível estabelecer correlação entre a produtividade de grãos de arroz e os componentes da produção, uma vez que nenhum desses apresentou dependência espacial nos seus dados.
\end{abstract}

Palavras-chave: Arroz irrigado, Oryza sativa L., regressões

\begin{abstract}
The rice is one of the main sources of the humanity's feeding. During the agricultural year 2009/2010, in Selvíria County, Mato Grosso do Sul State, in the Brazilian Savannah, an experiment was installed with rice upland in a Dystropherric Red Latosol (Typic Acrustox) under no-tillage, irrigated by central pivot, with the purpose of selecting the best components production to explain the variability the irrigated rice yield upland. The geostatistical grid was installed, to collect the data, with 120 sampling points, in an area of 3.0 ha and and homogeneous slope of $0.055 \mathrm{~m} \mathrm{~m}^{-1}$. The medium rice yield was of the 5980 $\mathrm{kg} \mathrm{ha}^{-1}$. For the simple lineal regressions, the number of spikelets grenades for panicle presented the best direct potential correlation with the yield rice, given for: $\mathrm{PGO}=115,5 . \mathrm{NEG}^{0,770}$. However, for the multiple lineal regressions, the equation equação $\mathrm{PGO}=2754,30-411,55 . \mathrm{NEG}-461,07 . \mathrm{NEC}+436,59$. NET it was the one that better she came to esteem the yield rice. However, spatial, it was not possible to establish correlation between the yield rice and the components production, once none of those it presented spatial dependence in their data.
\end{abstract}

Key words: Irrigated rice, Oryza sativa L., regressions

1 Parte da Dissertação de Mestrado em Agronomia do Primeiro Autor.

2 Prof. Dr. do Depto. de Agronomia, Instituto Federal de Educação, Ciência e Tecnologia de Mato Grosso, Campus Campo Novo do Parecis, MT. E-mail: flavio.dalchiavon@cnp.ifmt.edu.br

${ }^{3}$ Profs. do Dept ${ }^{\mathrm{o}}$ de Fitossanidade, Engenharia Rural e Solos, Faculdade de Engenharia de Ilha Solteira, UNESP, Ilha Solteira, SP. E-mail: morel@agr.feis.unesp.br; dreotti@agr.feis.unesp.br

${ }^{4}$ Mestrando(s) em Agronomia, Faculdade de Engenharia de Ilha Solteira, UNESP, Ilha Solteira, SP. E-mail: admar_coletti@ hotmail.com; agaione@hotmail.com; amiltonfs1@hotmail.com

* Autor para correspondência 


\section{Introdução}

O arroz (Oryza sativa L.) é uma das fontes básicas de alimentação da humanidade. No Brasil, o sistema de produção de arroz de terras altas ocupa aproximadamente $60 \%$ da área cultivada, correspondendo, contudo, a apenas $40 \%$ da produção, onde, em condições tecnificadas de cultivo, tem produzido acima de $4000 \mathrm{~kg} \mathrm{ha}^{-1}$ (SILVA, 2006). Segundo dados da Companhia Nacional de Abastecimento (2010), a produção de arroz na safra 2009/10, totalizou 11,2 milhões de toneladas. A área cultivada ocupou 2,7 milhões de hectares, com produtividade média de $4073 \mathrm{~kg} \mathrm{ha}^{-1}$.

$\mathrm{O}$ uso intensivo e inadequado dos solos acelera a degradação da matéria orgânica, principal componente da fertilidade dos solos (LOURENTE et al., 2010). Em contrapartida, o sistema plantio direto (SPD) tem se destacado como uma alternativa muito importante na produção de grãos, por permitir o cultivo das culturas sem que haja grandes impactos ambientais, contribuindo para maior preservação do solo e da água. Por proteger mais o solo, assume importância maior quando se trata do seu uso nos cerrados, que em geral, apresentam solos muito suscetíveis à erosão e com baixo teor de matéria orgânica (MOURA NETO; SOARES; AIDAR, 2002). Estes mesmos autores, em seu estudo, concluíram que o SPD constitui alternativa viável para a cultura do arroz de terras altas nas regiões de cerrado, pois em condições de menor disponibilidade hídrica e na ausência de adubação na semeadura, proporcionou produtividade de grãos igual ao plantio convencional.

A produtividade da cultura de arroz é definida por seus componentes, número de panículas $\mathrm{m}^{-2}$, número de espiguetas por panícula e massa de mil grãos (MARCHEZAN et al., 2005). Dewey e $\mathrm{Lu}$ (1959) foram os primeiros pesquisadores a utilizar esta metodologia em plantas de trigo. Os mesmos autores destacaram que os métodos de correlação linear e regressão múltipla foram os primeiros métodos a serem utilizados nas análises dos componentes da produção.
Tendo em vista que os componentes da produção influenciam a produtividade da cultura do arroz, destacam-se os trabalhos de Blanco et al. (1993) e Zaffaroni et al. (1998), onde relataram que o número de espiguetas por panícula e a massa de mil grãos foram os componentes que mais influenciaram na produtividade de grãos. Marchezan et al. (2005) observaram que a massa de mil grãos foi o componente da produção com maior efeito no aumento da produtividade do arroz, em contrapartida, o número de espiguetas chochas foi o mais influente na redução da produtividade, e Guimarães et al. (2006), verificando em seu estudo que o número de espiguetas chochas por panícula influenciou significativamente, de forma inversa e quadrática, a produtividade do arroz, ao passo que o número de espiguetas cheias por panícula influenciou direta e linearmente esta característica agronômica.

Diante do exposto, o presente trabalho teve por objetivo, através de coeficientes de correlação de Pearson e da modelagem de regressões lineares simples e múltiplas, selecionar os melhores componentes da produção para explicar a variabilidade da produtividade de grãos de arroz de terras altas irrigado.

\section{Material e Métodos}

O experimento foi realizado na Fazenda de Ensino e Pesquisa (FEP) em Selvíria, Estado do Mato Grosso do Sul, pertencente à Faculdade de Engenharia da Universidade Estadual Paulista (UNESP), entre as coordenadas geográficas 51'24'21" e 51'24'33" de Longitude Oeste e $20^{\circ} 20^{\prime} 56^{\prime \prime}$ e $20^{\circ} 21^{\prime} 03$ " de Latitude Sul, com altitude média de 342 metros, num Latossolo Vermelho distroférrico típico muito argiloso (EMBRAPA, 2006). O clima, conforme a classificação de Köppen, é do tipo Aw, que se caracteriza como tropical úmido megatérmico, com inverno seco e verão quente e chuvoso. A precipitação pluvial média anual é de aproximadamente $1232 \mathrm{~mm}$, temperatura média 
anual ao redor de $24,5^{\circ} \mathrm{C}$ e umidade relativa do ar entre 70 e $80 \%$.

Antes da instalação do experimento, foram coletadas 20 amostras simples de solo, nas profundidades de $0-0,10 \mathrm{~m}$ e $0,10-0,20 \mathrm{~m}$, das quais obteve uma amostra composta representativa para cada profundidade, para determinação das características químicas, cujos resultados estão contidos na Tabela 1.

Tabela 1. Características químicas do solo nas profundidades de 0-0,10 m e 0,10-0,20 m. Ano de 2009 .

\begin{tabular}{|c|c|c|c|c|c|c|c|c|c|c|c|c|}
\hline \multirow[b]{3}{*}{ Prof. } & \multicolumn{12}{|c|}{ Atributo químico ${ }^{\text {(a) }}$} \\
\hline & \multicolumn{3}{|c|}{ pH } & \multicolumn{7}{|c|}{ Complexo sortivo } & \multirow[b]{2}{*}{ V\% } & \multirow[b]{2}{*}{$\mathbf{m} \%$} \\
\hline & MO & $\mathrm{CaCl}_{2}$ & $\mathbf{P}$ & $\mathbf{K}^{+}$ & $\mathrm{Ca}^{2+}$ & $\mathrm{Mg}^{2+}$ & $\mathbf{H}^{+}+\mathbf{A} \mathbf{l}^{3+}$ & $\mathbf{A l}^{3+}$ & SB & CTC & & \\
\hline $\mathrm{m}$ & $\underset{\mathrm{dm}^{-3}}{\mathrm{~g}}$ & & $\begin{array}{c}\mathrm{mg} \\
\mathrm{dm}^{-3}\end{array}$ & --- & & ----1 & $\mathrm{ol}_{\mathrm{c}} \mathrm{dm}^{-3}$ & & & & & 0--- \\
\hline $0-0,10$ & 32 & 5,2 & 34 & 6,6 & 27 & 20 & 40 & 0,0 & 53,6 & 93,6 & 57,0 & 0,0 \\
\hline $0,10-0,20$ & 24 & 4,8 & 36 & 4,3 & 19 & 13 & 47 & 4,0 & 36,3 & 83,3 & 44,0 & 10,0 \\
\hline
\end{tabular}

(a) $\mathrm{MO}=$ matéria orgânica, $\mathrm{V} \%$ = índice de saturação por bases, $\mathrm{m} \%$ = índice de saturação por alumínio.

Fonte: Elaboração dos autores.

A área experimental foi cultivada durante onze anos no sistema plantio direto, com a sucessão de culturas soja ou milho/feijão, semeadas no verão e inverno, respectivamente. A área experimental foi previamente dessecada e em seguida semeada a cultivar de arroz IAC 202 em 14/11/2009, com linhas espaçadas de 0,34 $\mathrm{m}$ e densidade aproximada de 230 sementes $\mathrm{m}^{-2}$ com fornecimento de irrigação suplementar por aspersão (pivô central). Por ocasião da semeadura utilizou-se $100 \mathrm{~kg} \mathrm{ha}^{-1}$ da formulação 08-28-16 (N- $\left.\mathrm{P}_{2} \mathrm{O}_{5}-\mathrm{K}_{2} \mathrm{O}\right)$, e em cobertura $80 \mathrm{~kg} \mathrm{ha}^{-1}$ de $\mathrm{N}$ (sulfato de amônio), parcelado em 2 aplicações, metade aos 20 e o restante aos 44 dias após a semeadura (DAS). A colheita foi efetuada manualmente em 01/03/2010, aos 108 DAS, sendo seguida de trilha mecânica e secagem por ventilação natural.

Para a coleta dos dados, foi implantada uma malha geoestatística, cuja declividade do solo era de $0,055 \mathrm{~m} \mathrm{~m}^{-1}$. Foram definidas as direções $\mathrm{x}$ e y do sistema de coordenadas cartesianas, com 120 pontos amostrais distribuídos aleatoriamente numa área com 3,0 hectares $(322,00 \mathrm{~m}$ x 93,35 m), onde cada ponto amostral ficou constituído numa área aproximada de 250,5 $\mathrm{m}^{2}$. Foi utilizado um nível ótico comum para retirar as coordenadas $\mathrm{x}$ e $\mathrm{y}$, possibilitando a avaliação da dependência espacial entre os valores observados.

Os atributos avaliados foram: a) produtividade de grãos de arroz (PGO), b) número de panículas por área (NPA), c) número de espiguetas granadas por panícula (NEG), d) número de espiguetas chochas por panícula (NEC), e) número de espiguetas total por panícula (NET) e f) massa de mil grãos (MMG), sendo, à exceção da PGO, determinados no Laboratório de Análise de Sementes da Faculdade de Engenharia de Ilha Solteira - UNESP.

A PGO foi determinada em função da pesagem dos grãos colhidos no entorno do ponto amostral, em 4 linhas de semeadura numa área útil de 1,85 $\mathrm{m}^{2}(1,36 \mathrm{~m} \times 1,36 \mathrm{~m})$ e extrapolada para $\mathrm{kg} \mathrm{ha}^{-1}$ de grãos em casca (13\% base úmida). O NPA foi determinado mediante a contagem das panículas em um metro de linha em cada ponto amostral e extrapolado para a área de $1 \mathrm{~m}^{2}$. O NEG, NEC e o NET foram determinados mediante a coleta ao acaso de 15 panículas em cada ponto amostral na fase de maturação dos grãos. A separação das espiguetas chochas das granadas foi realizada por fluxo de ar. E por fim, para a determinação da MMG, foram utilizadas amostras de grãos de cada 
ponto amostral, segundo metodologia proposta por Brasil (2009).

Para cada atributo estudado foi efetuada a análise descritiva com o auxilio da estatística clássica, utilizando o Software SAS (SCHLOTZHAVER; LITTELL, 1997), sendo calculadas a média, mediana, moda, valores mínimo e máximo, desvio padrão, coeficiente de variação, curtose, assimetria e distribuição de frequência. Seguidamente foram identificados os outliers, conforme identificação do gráfico de ramos e folhas, efetuando-se sua substituição pelo valor médio dos circunvizinhos. Assim, para testar a hipótese da normalidade, ou da lognormalidade dos atributos, foi utilizado o teste de Shapiro e Wilk (1965) a 5\%.

Foi montada a matriz de correlação, objetivando efetuar as correlações lineares simples para as combinações, duas a duas, entre todos os atributos estudados, a partir das quais foram efetuadas as modelagens das regressões lineares simples com a planilha de cálculos Excel. Por outro lado, utilizando-se o pacote computacional SAS, foram efetuadas as regressões lineares múltiplas da PGO (variável dependente) em função dos componentes da produção do arroz (variáveis independentes), no intuito de selecionar aqueles componentes que, nos devidos casos, proporcionariam as melhores equações para estimar a PGO, por intermédio do stepwise, a $10 \%$ de probabilidade para a inclusão e exclusão de variáveis no modelo. O desempenho das equações foi analisado pelo coeficiente de determinação $\left(\mathrm{R}^{2}\right)$ e pela contribuição de cada componente no modelo, estimada pelo aumento observado na soma de quadrados devido à regressão, quando da adição de cada variável no modelo, conforme Maia, Morais e Oliveira et al. (2001).

Para cada atributo foi analisada a dependência espacial pelo cálculo do semivariograma simples, com base nos pressupostos de estacionaridade da hipótese intrínseca pelo uso do pacote Gamma Design Software $7.0\left(\mathrm{GS}^{+}, 2004\right)$. Os ajustes dos semivariogramas simples, em função de seus modelos, foram efetuados prioritariamente pela seleção inicial de: 1) a menor soma dos quadrados dos desvios (RSS), 2) o maior coeficiente de determinação $\left(r^{2}\right)$ e 3$)$ o maior avaliador da dependência espacial (ADE), conforme Dalchiavon et al. (2011). Entretanto, para os atributos (ATR) que não apresentaram dependência espacial, isto é, na ausência de estacionaridade, retirou-se a tendência dos dados por meio da técnica da regressão múltipla polinomial, conforme preceitos de Davis (1986). Assim, eles ficaram precedidos do símbolo \# quando referidos na análise semivariográfica e na validação cruzada. Já quando referidos no mapa de krigagem e/ou co-krigagem ficaram precedidos do símbolo $£$. A decisão final do modelo que representou o ajuste foi atestada pela validação cruzada, assim como para a definição do tamanho da vizinhança que proporcionou a melhor malha de krigagem. Para cada atributo foram relacionados o efeito pepita $\left(\mathrm{C}_{\mathrm{o}}\right)$, o patamar $\left(\mathrm{C}_{\mathrm{o}}+\mathrm{C}\right)$ e o alcance $\left(\mathrm{A}_{\mathrm{o}}\right)$. A análise do $\mathrm{ADE}$ foi efetuada conforme a seguinte expressão $\left(\mathrm{GS}^{+}, 2004\right)$ :

$$
\mathrm{ADE}=\left[\mathrm{C} /\left(\mathrm{C}+\mathrm{C}_{\mathrm{o}}\right)\right] .100
$$

onde: ADE é o avaliador da dependência espacial; $\mathbf{C}$, a variância estrutural; e $\mathbf{C}+\mathbf{C}_{\mathbf{o}}$, o patamar. A interpretação proposta para o $\mathrm{ADE}$ foi a seguinte: a) $\mathrm{ADE}<20 \%=$ variável espacial de muito baixa dependência (MB); b) $20 \% \leq \mathrm{ADE}<40 \%=$ baixa dependência (BA); c) 40\% $\leq \mathrm{ADE}<60 \%=$ média dependência (ME); d) $60 \% \leq \mathrm{ADE}<80 \%=$ alta dependência (AL), e e) $80 \% \leq \mathrm{ADE}<100 \%=$ muito alta dependência (MA).

\section{Resultados e Discussão}

Para os componentes da produção número de panículas por área (NPA), número de espiguetas granadas por panícula (NEG) e número de espiguetas total por panícula (NET), os CVs observados foram classificados como médio (Tabela 2), concordando com os estudos de Höfs et al. (2004) e Silva et al. (2009), para o NPA, com Cazetta et al. (2008) e Guimarães (2008), para o NEG, e com Zaratin et al. 
(2004) e Silva et al. (2009), para o NET. Por outro lado, baixo CV foi verificado para o componente da produção massa de mil grãos (MMG), estando de acordo com àqueles CVs observados por Crusciol et al. (2003), Meira et al. (2005) e Fageria e Santos (2007).

Tabela 2. Análise descritiva de alguns componentes da produção e da produtividade do arroz em um Latossolo Vermelho distroférrico sob sistema plantio direto. Selvíria - MS, 2009/2010.

\begin{tabular}{|c|c|c|c|c|c|c|c|c|c|c|}
\hline \multirow{3}{*}{ Atributo (a) } & \multicolumn{10}{|c|}{ Medidas estatísticas descritivas } \\
\hline & \multirow{2}{*}{ Média } & \multirow{2}{*}{ Mediana } & \multicolumn{2}{|c|}{ Valor } & \multirow{2}{*}{$\begin{array}{l}\text { Desvio } \\
\text { Padrão }\end{array}$} & \multicolumn{3}{|c|}{ Coeficiente } & \multicolumn{2}{|c|}{$\begin{array}{l}\text { Probabilidade } \\
\text { do teste }^{(\mathbf{b})}\end{array}$} \\
\hline & & & Mínimo & Máximo & & $\begin{array}{c}\text { Variação } \\
(\%)\end{array}$ & Curtose & Assimetria & $\operatorname{Pr}<\mathbf{W}$ & DF \\
\hline $\begin{array}{c}\text { PGO (kg } \\
\left.\text { ha }^{-1}\right)\end{array}$ & 5980 & 5933 & 2365 & 9117 & 1328 & 22,2 & 0,069 & 0,071 & 0,715 & NO \\
\hline NPA & 260 & 256 & 129 & 379 & 50,96 & 19,6 & $-0,412$ & $-0,002$ & 0,778 & NO \\
\hline NEG & 164 & 164 & 88 & 218 & 23,89 & 14,5 & 0,546 & $-0,319$ & 0,344 & NO \\
\hline NEC & 36 & 36 & 11 & 57 & 9,94 & 27,4 & $-0,394$ & $-0,186$ & 0,467 & NO \\
\hline NET & 201 & 201 & 139 & 255 & 25,00 & 12,5 & $-0,279$ & $-0,211$ & 0,195 & NO \\
\hline MMG (g) & 24,60 & 24,54 & 21,43 & 27,70 & 1,422 & 5,78 & $-0,404$ & $-0,002$ & 0,327 & NO \\
\hline
\end{tabular}

(a) PGO, NPA, NEG, NEC, NET e MMG são respectivamente a produtividade de grãos de arroz, número de panículas área, número de espiguetas granadas por panícula, número de espiguetas chochas por panícula, número de espiguetas total por panícula e massa de mil grãos; (b) DF = distribuição de frequência, sendo NO do tipo normal.

Fonte: Elaboração dos autores.

Todos os atributos pesquisados apresentaram distribuição de frequência do tipo normal (Tabela 2), uma vez que suas probabilidades oscilaram entre 0,195 (NET) e 0,778 (NPA), assim como os coeficientes de assimetria e curtose próximos de zero. Observa-se ainda que o valor médio da PGO $\left(5980 \mathrm{~kg} \mathrm{ha}^{-1}\right)$ foi superior às médias, todas com a cultivar IAC 202, de $4922 \mathrm{~kg} \mathrm{ha}^{-1}$ (SILVA et al., 2002); de $5491 \mathrm{~kg} \mathrm{ha}^{-1}$ (CARVALHO-PUPATTO; BÜLL; CRUSCIOL, 2004); de $5032 \mathrm{~kg} \mathrm{ha}^{-1}$ (SILVA, 2006); de $5367 \mathrm{~kg} \mathrm{ha}^{-1}$ (GUIMARÃES, 2008). Superou ainda a produtividade média nacional da safra 2009/10, que foi de $4073 \mathrm{~kg} \mathrm{ha}^{-1}$ (CONAB, 2010). A considerável produtividade média de arroz obtida neste estudo, possivelmente está associada à precipitação pluviométrica total acumulada para o período experimental (822 mm), pois, conforme Medeiros, Soares e Guimarães (2005), o teor de água no solo é fator fundamental para o desempenho da cultura do arroz no plantio direto. Tal precipitação (822 mm) é considerada alta para a demanda da cultura, uma vez que a necessidade hídrica total para o cultivo do arroz de terras altas está em torno de $600 \mathrm{~mm}$ (EMBRAPA, 2003). Aliada à questão da precipitação, a disponibilidade de nutrientes à cultura também não foi fator limitante, pois estes estavam prontamente disponíveis na solução do solo em teores médios $(\mathrm{P})$ e altos $(\mathrm{K}, \mathrm{Ca}$ e $\mathrm{Mg})$, conforme caracterização química inicial do solo (Tabela 1).

Em relação aos componentes da produção, os valores médios obtidos foram de 260, 164, 36, $201 \mathrm{e}$ 24,60 g, respectivamente, para o NPA, NEG, NEC, NET e MMG (Tabela 2). O número de espiguetas é um componente da produção muito dependente das condições de manejo, principalmente na semeadura, cultivar, época, local, fertilidade do solo e adubação. Contudo, pelas condições de sistema plantio direto já consolidado e pelo uso de irrigação suplementar (pivô central), aparentemente não houve problemas na definição deste componente, pois pela boa fertilidade do solo na área em questão e pela não 
restrição hídrica, o valor de 260 panículas $\mathrm{m}^{-2}$ foi bem superior aos valores observados por Crusciol et al. (2003) e Meira et al. (2005) em áreas e condições semelhantes ao presente estudo. Cabe salientar que o número de panículas é definido durante o período de germinação a dez dias depois que o primórdio da panícula é visível (MACHADO, 1994), já que existe uma função direta com o número de colmos, dependendo, portanto, dos fatores genéticos (cultivar) e ambientais, que no presente trabalho não foram impeditivos nas condições de terras altas irrigado por aspersão e em solo de boa fertilidade, o que indica que o cultivar apresentou boa capacidade de perfilhamento.

Segundo Yoshida (1981a,1981b), o número total de espiguetas é influenciado por fatores genéticos e condições externas vigentes durante a fase reprodutiva, mais precisamente do início da fase reprodutiva até cinco dias que antecedem o florescimento. Assim, pela boa fertilidade do solo e disponibilidade hídrica durante o desenvolvimento da cultura, verifica-se um alto valor de NET, com baixo número de espiguetas chochas (NEC), e portanto, bons valores de NEG (Tabela 2), que expressam a boa fertilidade das espiguetas que se tornaram grãos. Este componente da produção é dependente da meiose do grão do pólen, da antese, da polinização, da fertilização e da translocação de carboidratos, e é influenciada por circunstâncias ambientais, especialmente ao redor dos 10 dias que antecedem o florescimento, assim como níveis excessivos de fertilizantes nitrogenados (MACHADO, 1994), elemento este não deficitário no presente trabalho pela condição de não limitação hídrica e aplicação em cobertura de $80 \mathrm{~kg} \mathrm{ha}^{-1}$ de $\mathrm{N}$, na forma de sulfato de amônio, e, portanto com baixo risco de perdas.

Com relação à $\mathrm{MMG}$, este é um componente que é determinado durante as duas semanas que precede a antese, e do desenvolvimento da cariopse após o florescimento. Consequentemente, depende da translocação de carboidratos, nos primeiros sete dias, para enchimento do grão no sentido de seu comprimento, e nos sete dias que se seguem, para aumentar a largura e a espessura do grão (MACHADO, 1994). Novamente pelas boas condições de clima, aliada a irrigação suplementar e pela boa fertilidade do solo, os valores médios de 24,60 g demonstraram que houve ótima translocação de assimilados para os grãos, pois em condições semelhantes de local e solo, Meira et al. (2005) e Buzetti et al. (2006) verificaram valores próximos também em condições de terras altas irrigado por aspersão para a mesma cultivar IAC 202.

Em trabalhos de avaliação dos componentes da produção de arroz, Silva et al. (2002) constataram valores de 214, 159, 62, 223 e 24,00 g para os mesmos componentes da produção (NPA, NEG, NEC, NET e MMG). Entretanto, o NEG e a MMG apresentaram maior proximidade de valores quando comparados ao presente estudo. Por outro lado, Farinelli et al. (2004) descreveram valores médios de 228 (NEG), 116 (NEC), 344 (NET) e 23,39 g (MMG), discordando dos dados ora apresentados. Já Silva et al. (2009), relataram valores inferiores quando comparados a este estudo, sendo $210,187 \mathrm{e}$ 21,5 g para os componentes da produção NPA, NET e MMG, respectivamente. Entretanto, cabe salientar que os trabalhos dos mencionados autores possuíram como causas de variação épocas de aplicação da adubação potássica (SILVA et al., 2002), doses de adubação nitrogenada e potássica (FARINELLI et al., 2004) e avaliação de cultivares (SILVA et al., 2009), o que provavelmente tenha contribuído para as diferenças constatadas em relação ao presente trabalho, uma vez que pela discussão anterior, os componentes da produção são extremamente dependentes de fatores bióticos e/ou abióticos, em diferentes estádios de desenvolvimento da cultura.

Para as correlações de Pearson entre a produtividade de grãos de arroz e seus componentes da produção (Tabela 3), foram significativos os pares PGO x NPA $\left(r=0,229^{*}\right)$, PGO x NEG $\left(r=0,475^{* *}\right)$, PGO xNEC $\left(r=-0,232^{*}\right)$ ePGO xNET $(r=0,362 * *)$, confirmando a estreita relação da produtividade de grãos de arroz com seus componentes da produção, 
principalmente em relação ao NEG e ao NPA, que foram os dois que mais contribuíram para o aumento da produção de grãos de arroz. Tais constatações também foram confirmadas por Fageria (2000), que relatou correlação significativa da produtividade de grãos de arroz em função do número de panículas $(r=0,570 * *)$, e por Guimarães et al. (2006), que correlacionaram positiva e significativamente a produtividade de grãos de arroz com o número de espiguetas por panícula. Portanto, é importante que o orizicultor realize adequadamente o manejo agrícola, para que a cultura possa produzir o maior número possível de panículas e espiguetas granadas, uma vez que estas, consequentemente, determinarão a produção.

Cabe salientar que o número de espiguetas chochas por panícula, influiu negativa e significativamente na produtividade de grãos de arroz, conforme o (Tabela 3), corroborando as constatações de Marchezan et al. (2005).

Tabela 3. Coeficientes de correlação de Pearson entre alguns atributos da produtividade do arroz em um Latossolo Vermelho distroférrico sob sistema plantio direto. Selvíria - MS, 2009/2010.

\begin{tabular}{cccccc}
\hline \multirow{2}{*}{ Atributos $^{(a)}$} & \multicolumn{5}{c}{ Coeficiente de correlação $^{(\mathbf{b})}$} \\
\cline { 2 - 5 } & $\mathbf{P G O}$ & NPA & NEG & NEC & NET \\
\hline NPA & $\mathbf{0 , 2 2 9 *}$ & & & \\
NEG & $\mathbf{0 , 4 7 5 * *}^{*}$ & $\mathbf{0 , 1 8 7 ^ { * }}$ & & & \\
NEC & $\mathbf{0 , 2 3 2 *}_{\text {NET }}$ & $-0,142$ & $-0,099$ & & \\
MMG & $\mathbf{0 , 3 6 2 *}$ & 0,123 & $\mathbf{0 , 9 1 8 * *}$ & $\mathbf{0 , 3 0 4 * *}$ & \\
& 0,150 & $-0,023$ & 0,018 & $\mathbf{- 0 , 4 4 5 * *}$ & $-0,160$ \\
\hline
\end{tabular}

(a) Vide Tabela 2; (b) ** significativo a 1\%, * significativo a 5\%.

Fonte: Elaboração dos autores.

Tendo em vista a importância agronômica deste estudo, foram modeladas as principais equações de regressão linear simples $[\mathrm{PGO}=\mathrm{f}(\mathrm{NPA})$ e $\mathrm{PGO}=\mathrm{f}(\mathrm{NEG})]$ e apresentadas nas Figuras 1 e 2. Em relação à regressão $\mathrm{PGO}=\mathrm{f}(\mathrm{NPA})$, foi modelada uma equação do tipo potencial direta (Figura 1), cujo coeficiente de correlação (r) foi $0,257 * *$, significativo a $1 \%$. Trabalhando-se na equação de regressão obtida e utilizando-se o valor mínimo (129) e máximo (379) da variável independente NPA (Tabela 2), verificou-se que a PGO variou entre $4740 \mathrm{~kg} \mathrm{ha}^{-1}$ e $6520 \mathrm{~kg} \mathrm{ha}^{-1}$, respectivamente. Por outro lado, quando na equação considerou-se o valor médio do NPA (260), a PGO foi estimada em $5832 \mathrm{~kg} \mathrm{ha}^{-1}$.

Da mesma forma, na Figura 2 está exposta a equação de regressão $\mathrm{PGO}=\mathrm{f}(\mathrm{NEG})$, a qual foi representada pelo modelo polinomial do tipo potencial direta $(r=0,502 * *)$. Assim, 50,2\% da variação da PGO puderam ser explicadas pela variação do NEG. Explorando a referida equação de regressão, é possível observar que se variando o NEG entre 88 a 218 (Tabela 2), a estimativa da PGO passará de $3629 \mathrm{~kg} \mathrm{ha}^{-1} \mathrm{a}$ $7298 \mathrm{~kg} \mathrm{ha}^{-1}$, respectivamente. Analogamente, ao considerar o valor médio do NEG (164) obtido neste experimento, poderá ser estimada uma PGO de $5862 \mathrm{~kg} \mathrm{ha}^{-1}$, valor este próximo à PGO desta pesquisa. Neste sentido, Guimarães et al. (2006), que avaliando o comportamento do arroz de terras altas (cultivar canastra) em sistema plantio direto, também modelou regressão entre $\mathrm{PGO}=\mathrm{f}(\mathrm{NEG})$, cuja equação, de comportamento linear direta, explicou $68 \%$ da variação da produtividade do arroz $\left(\mathrm{R}^{2}=0,68^{* *}\right)$. Estes autores tiveram a produtividade do arroz variando entre $3067 \mathrm{~kg} \mathrm{ha}^{-1}$ e $4691 \mathrm{~kg}$ $\mathrm{ha}^{-1}$ quando o número de espiguetas granadas por panícula variou entre 95 e 175 . Por outro lado, a produtividade média foi estimada em $3583 \mathrm{~kg}$ 
ha ${ }^{-1}$ quando o valor médio de espiguetas granadas por panícula $(120,4)$ foi considerado na regressão obtida.

Portanto, ambas as equações podem perfeitamente ser utilizadas para se estimar a produtividade de grãos de arroz, quando as condições de cultivo forem semelhantes às da presente pesquisa. Entretanto, em função da equação $\mathrm{PGO}=115,5$. $\mathrm{NEG}^{0,770}$ ter apresentado o maior coeficiente de correlação $\left(\mathrm{r}=0,502^{* *}\right)$, Figura 2, significativa a $1 \%$, recomenda-se a sua utilização, uma vez que há elevada probabilidade desta estimar com maior precisão a produtividade de grãos de arroz.

Figura 1. Equação de regressão da produtividade de grãos de arroz de terras altas em função do número de panículas por área em um Latossolo Vermelho distroférrico sob sistema plantio direto. Selvíria - MS, 2009/2010.

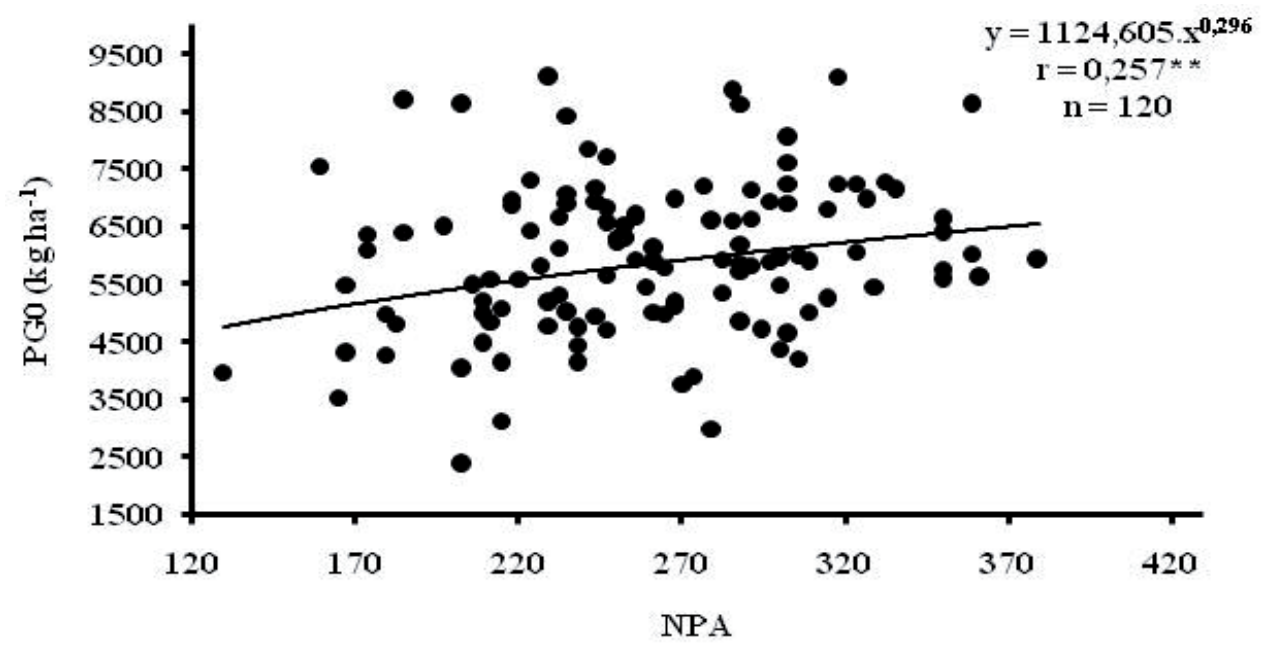

Fonte: Elaboração dos autores.

Figura 2. Equação de regressão da produtividade de grãos de arroz de terras altas em função do número de espiguetas granadas por panícula em um Latossolo Vermelho distroférrico sob sistema plantio direto. Selvíria - MS, 2009/2010.

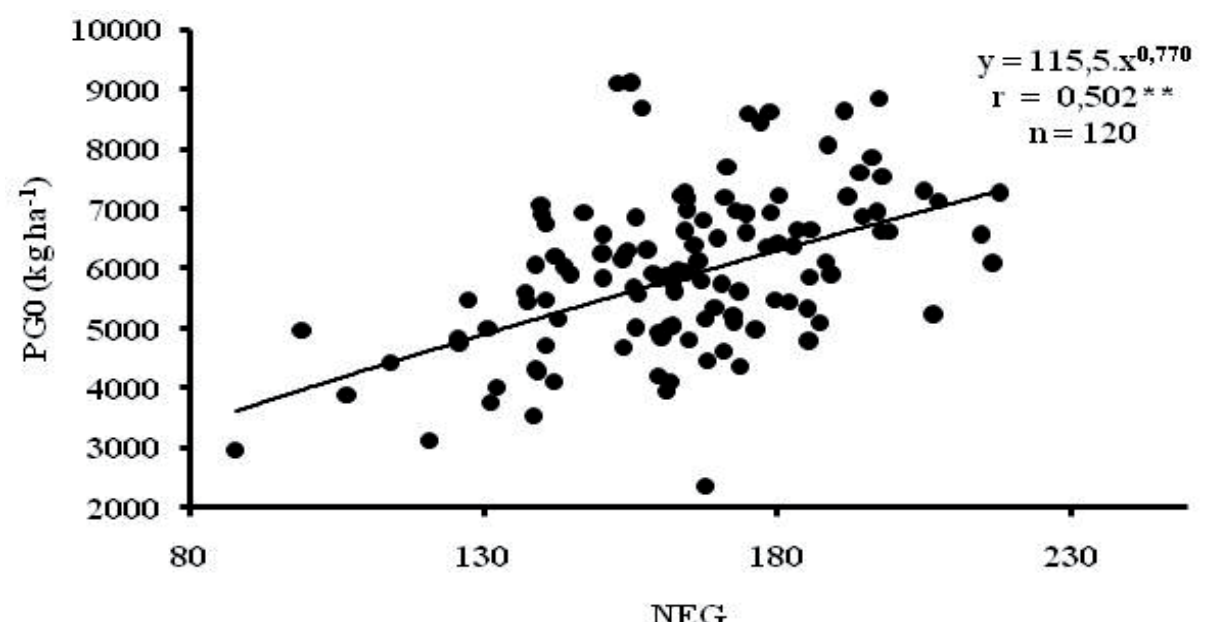

Fonte: Elaboração dos autores. 
$\mathrm{Na}$ Tabela 4 estão apresentadas as regressões lineares múltiplas ajustadas para estimar a produtividade de grãos de arroz (variável dependente) em função dos componentes da produção (variáveis independentes), o número de observações e seus respectivos coeficientes de determinação $\left(\mathrm{R}^{2}\right)$. Assim, para a primeira variável (NEG) adicionada no ajuste da regressão, houve uma explicação de $22,4 \%$ da PGO $\left(\mathrm{R}^{2}=0,224\right)$. Este resultado está de acordo com aquele apresentado na Tabela 3, que evidencia a maior correlação da PGO com o componente da produção NEG. Por outro lado, a combinação do NEG e NEC explicou 25,9\% da $\mathrm{PGO}$, indicando um pequeno acréscimo quando o ajuste da regressão adicionou mais uma variável. Contudo, uma terceira seleção de variáveis com maior precisão na explicação da PGO adicionou o NET. Este ajuste da regressão conseguiu explicar $28,8 \%$ da PGO, representando um acréscimo em $\mathrm{R}^{2}$ de $6,4 \%$, quando comparada a equação que considera somente o NEG.

As demais influências na PGO ficaram por conta de outros fatores que não entraram nos modelos por não serem significativos a $10 \%$ de probabilidade. A explicação proposta com base na regressão linear múltipla demonstrou a implicação de cada componente da produção (variável independente) pesquisado na produtividade de grãos de arroz, levando em consideração seus valores, o que permitiu classificar qual foi a real contribuição de cada variável componente da produção no modelo ajustado. Neste contexto, foi verificado que o maior peso equivalente da PGO no modelo ajustado foi devido ao NEG (77,67\%), seguido pelo NEC e NET (Tabela 5). Segundo Maia, Morais e Oliveira (2001), o uso do peso em porcentagem leva a uma precisão maior no diagnóstico, pois todas as variáveis independentes incluídas nos modelos estão na mesma escala, no caso, expressos em valores relativos, fato corroborado pelos coeficientes de determinação apresentados na Tabela 4.

Portanto, conforme verificado na Tabela 4, a equação de regressão linear múltipla de melhor desempenho (maior $\mathrm{R}^{2}$ ), significativa a $1 \%$, foi: $\mathrm{PGO}=2754,30-411,55 . \mathrm{NEG}-461,07 . \mathrm{NEC}+436,59$. NET, que estimou uma PGO de $6416 \mathrm{~kg} \mathrm{ha}^{-1}$. O componente da produção que mais contribuiu para o ajuste do referido modelo foi o NEG, estimada pela sua maior contribuição na soma de quadrados devido à regressão $(77,67 \%)$, como pode ser confirmado na Tabela 5.

Tabela 4. Equações de regressão linear múltipla obtidas para estimar a produtividade de grãos de arroz pelo método Stepwise, número de observações $(\mathrm{N})$ e coeficiente de determinação $\left(\mathrm{R}^{2}\right)$ para os componentes da produção. Selvíria - MS, 2009/2010.

\begin{tabular}{lccc}
\hline \multicolumn{1}{c}{ Equação de Regressão } & PGO Estimada/Real & N & $\mathbf{R}^{2}$ \\
\hline PGO $=1661,20+26,29$. NEG $^{* *}$ & $5973 / 5980$ & 120 & $0,224^{* *}$ \\
PGO $=2740,97+25,29$. NEG $^{* *}-25,20$. NEC $^{*}$ & $5981 / 5980$ & 120 & $0,259^{* *}$ \\
PGO $=2754,30-411,55$. NEG $^{*}-461,07$. NEC $^{*+436,59 . N E T *}$ & $6416 / 5980$ & 120 & $0,288^{* *}$ \\
\hline
\end{tabular}

Significativo à $5 \%$; ** Significativo à $1 \%$ de probabilidade.

Fonte: Elaboração dos autores. 
Tabela 5. Peso na soma de quadrados e peso em porcentagem dos componentes da produção em cada modelo ajustado pela regressão linear múltipla obtida pelo método Stepwise. Selvíria - MS, 2009/2010.

\begin{tabular}{ccc}
\hline Componente da Produção $^{(a)}$ & Peso na Soma de Quadrados & Peso em Porcentagem \\
\hline NEG & 46.945 .214 & 77,67 \\
NEC & 54.351 .815 & 12,26 \\
NET & 60.440 .391 & 10,07 \\
\hline
\end{tabular}

(a) Vide Tabela 2.

Fonte: Elaboração dos autores.

$\mathrm{Na}$ análise geoestatística, com exceção da PGO, que apresentou dependência espacial, todos os componentes da produção apresentaram efeito pepita puro. O efeito pepita puro denotou que o comportamento dessas variáveis regionalizadas foi totalmente aleatório, revelando a descontinuidade do semivariograma em distâncias menores que as amostradas, indicando a necessidade de repensá-la. Na Figura 3 estão evidenciados o semivariograma e o mapa de krigagem da produtividade de grãos de arroz, havendo a necessidade de extrair a tendência nos seus dados. Assim, foi ajustado o modelo semivariográfico esférico, com coeficiente de determinação espacial $\left(\mathrm{r}^{2}\right)$ de 0,771 e dependência espacial média $(52,2 \%)$. O alcance geoestatístico foi de $47,0 \mathrm{~m}$. O conhecimento do alcance geoestatístico é muito importante uma vez que ele determina a distância na qual uma variável regionalizada, modelada pelo semivariograma, apresenta continuidade espacial. Em contrapartida, para distâncias maiores que aquela determinada pelo alcance geoestatístico, o comportamento espacial da variável regionalizada passa a ser totalmente aleatório.

Foi constatado que nas regiões sul, noroestesudoeste e nordeste, ocorreram os mais elevados valores da £PGO (5878 a $7619 \mathrm{~kg} \mathrm{ha}^{-1}$ ) (Figura 3b). Em contrapartida, nas demais regiões ocorreram os mais baixos valores da £PGO (3557-5878 kg $\left.\mathrm{ha}^{-1}\right)$, indicando manchas com produtividades extremamente variadas, concordando com Molin et al. (2007), que também verificaram em seu estudo, a presença de diferentes produtividades de milho safrinha em toda a área experimental.

Figura 3. Semivariograma e Mapa de krigagem da produtividade de grãos de arroz ( Vermelho distroférrico sob plantio direto. Números entre parênteses são, respectivamente, valor do efeito pepita $\left(\mathrm{C}_{0}\right)$, contribuição (C C $_{1}$ e alcance (a). Selvíria - MS, 2009/2010.

$\mathrm{a}$

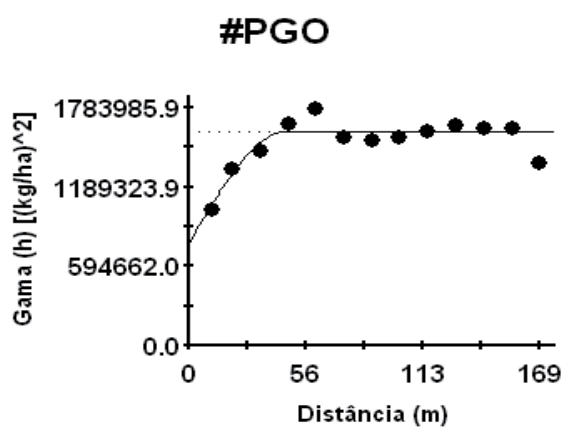

b

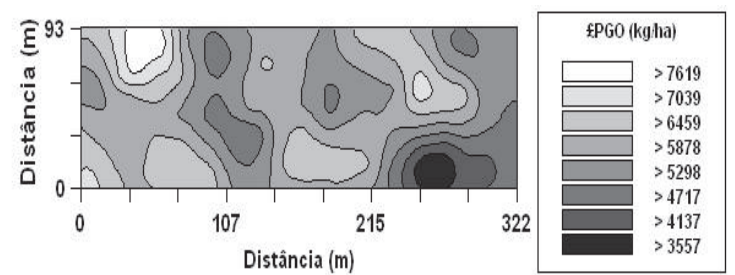

Fonte: Elaboração dos autores. 
Como pode ser constatado, para a avaliação geoestatística dos componentes da produção de grãos de arroz, que apresentaram efeito pepita puro, representando aquela variância que não pôde ser detectada pelos semivariogramas, devem-se adotar coletas amostrais à distâncias menores que as adotadas neste estudo, seja para minimizar a ocorrência de um erro qualquer, seja para confirmar se realmente esses componentes da produção possuem distribuição espacial totalmente aleatória, ou ainda o contrário, se a continuidade dos semivariogramas se dá à distâncias menores que as amostradas.

\section{Conclusões}

A produtividade média de grãos de arroz foi de $5980 \mathrm{~kg} \mathrm{ha}^{-1}$.

Para as regressões lineares simples, o número de espiguetas granadas por panícula apresentou a melhor correlação potencial direta com a produtividade de grãos de arroz, dada por: PGO $=115,5 \cdot \mathrm{NEG}^{0,770}$. Entretanto, para as regressões lineares múltiplas, a equação $\mathrm{PGO}=2754,30$ 411,55.NEG-461,07.NEC+436,59.NET foi a que melhor se apresentou para estimar a produtividade de grãos de arroz.

Espacialmente, não foi possível estabelecer correlação entre a produtividade de grãos de arroz e os componentes da produção, uma vez que nenhum desses apresentou dependência espacial nos seus dados.

\section{Agradecimento}

Os autores agradecem a Coordenação de Aperfeiçoamento de Pessoal de Nível Superior (CAPES) pelo auxílio financeiro concedido ao primeiro autor.

\section{Referências}

BLANCO, P. H.; VIDA, F. B. P.; CASTRO, L. A.; PORTO, A. Análisis del crecimiento y componentes de rendimento en cultivares de arroz. In: REUNIÃO DA CULTURA DO ARROZ IRRIGADO, 20., 1993, Pelotas. Anais... Pelotas: Embrapa-CPACT, 1993. p. 74-77.

BRASIL. Ministério da Agricultura, Pecuária e Abastecimento. Regras para análise de semente. Ministério da Agricultura, Pecuária e Abastecimento. Secretaria de Defesa Agropecuária. Brasília: Mapa/ACS, 2009. 399 p.

BUZETTI, S.; BAZANINI, G. C.; FREITAS, J. G.; ANDREOTTI, M.; ARF, O.; SÁ, M. E.; MEIRA, F. A. Resposta de cultivares de arroz a doses de nitrogênio e do regulador de crescimento cloreto de clormequat. Pesquisa Agropecuária Brasileira, Brasília, v. 41, n. 12, p. 1731-1737, 2006.

CARVALHO-PUPATTO, J. G.; BÜLL, L. T.; CRUSCIOL, C. A. C. Atributos químicos do solo, crescimento radicular e produtividade do arroz de acordo com a aplicação de escórias. Pesquisa Agropecuária Brasileira, Brasília, v. 39, n. 12, p. 1213-1218, 2004.

CAZETTA, D. A.; ARF, O.; BUZETTI, S.; SÁ, M. E.; RODRIGUES, R. A. F. Desempenho do arroz de terras altas com a aplicação de doses de nitrogênio e em sucessão às culturas de cobertura do solo em sistema de plantio direto. Revista Bragantia, Campinas, v. 67, n. 2, p. 471-479, 2008.

COMPANHIA NACIONAL DE ABASTECIMENTO CONAB. Acompanhamento da safra brasileira: grãos décimo segundo levantamento, setembro 2010. Brasília: CONAB, 2010. 41 p.

CRUSCIOL, C. A. C.; ARF, O.; SORATTO, R. P.; ANDREOTTI, M. Produtividade do arroz de terras altas sob condições de sequeiro e irrigado por aspersão em função do espaçamento entre fileiras. Agronomia, Rio de Janeiro, v. 37, n. 1, p. 10-15, 2003.

DALCHIAVON, F. C.; CARVALHO, M.P.; NOGUEIRA, D. C.; ROMANO, D.; ABRANTES, F. L.; ASSIS, J. T.; OLIVEIRA, M. S. Produtividade da soja e resistência mecânica à penetração do solo sob sistema plantio direto no cerrado brasileiro. Pesquisa Agropecuária Tropical, Goiânia, v. 41, n. 1, p. 8-19, 2011.

DAVIS, J. C. Statistics and analysis in geology. 2. ed. New York: John Wiley, 1986. 646 p.

DEWEY, D. R.; LU, K. H. A correlation path coefficient analysis of components of crested wheatgrass seed production. Agronomy Journal, Madison, v. 51, n. 2, p. 515-518, 1959. 
EMPRESA BRASILEIRA DE PESQUISA AGROPECUÁRIA - EMBRAPA. Cultivo do arroz de terras altas. Santo Antônio de Goiás: EMBRAPA, 2003. (Sistemas de produção, n. 1). Disponível em: $<$ http:// sistemasdeproducao.cnptia.embrapa.br/FontesHTML/ Arroz/ArrozTerrasAltas/index.htm>. Acesso em: 25 out. 2010.

Sistema brasileiro de classificação de solos. 2. ed. Rio de Janeiro: Embrapa, 2006. 306 p.

FAGERIA, N. K. Eficiência do uso de potássio pelos genótipos de arroz de terras altas. Pesquisa Agropecuária Brasileira, Brasília, v. 35, n. 10, p. 2115-2120, 2000.

FAGERIA, N. K.; SANTOS, A. B. dos. Resposta do arroz irrigado à adubação verde e química no Estado de Tocantins. Revista Brasileira de Engenharia Agrícola e Ambiental, Campina Grande, v. 11, n. 4, p. 387-392, 2007.

FARINELLI, R.; PENARIOL, F. G.; FORNASIERI FILHO, D.; BORDIN, L. Características agronômicas de arroz de terras altas sob plantio direto e adubação nitrogenada e potássica. Revista Brasileira de Ciência do Solo, Viçosa, v. 28, n. 3, p. 447-454, 2004.

$G S^{+}$: geostatistics for environmental sciences. 7. ed. Michigan, Plainwell: Gamma Desing Software, 2004. $159 \mathrm{p}$.

GUIMARÃES, G. L. Plantas de cobertura e adubação nitrogenada em cultivares de arroz de terras altas irrigadas no cerrado. 2008. Tese (Doutorado em Agronomia) - Faculdade de Engenharia. Universidade Estadual Paulista, Ilha Solteira.

GUIMARÃES, C. M.; STONE, L. F.; CASTRO, E. M. Comportamento de cultivares de arroz de terras altas no sistema plantio direto em duas profundidades de adubação. Bioscience Journal, Uberlândia, v. 22, n. 1, p. 53-59, 2006.

HÖFS, A.; SCHUCH, L. O. B.; PESKE, S. T.; BARROS, A. C. S. A. Efeito da qualidade fisiológica das sementes e da densidade de semeadura sobre o rendimento de grãos e qualidade industrial em arroz. Revista Brasileira de Sementes, Londrina, v. 26, n. 2, p. 54-62, 2004.

LOURENTE, E. R. P.; MERCANTE, F. M.; MARCHETTI, M. E.; SOUZA, L. C. F.; SOUZA, C. M. A.; GONÇALVES, M. C.; SILVA, M. A. G. Rotação de culturas e relações com atributos químicos e microbiológicos do solo e produtividade do milho. Semina: Ciências Agrárias, Londrina, v. 31, n. 4, p. 829$842,2010$.

MACHADO, J. R. Desenvolvimento da planta $e$ produtividade de grãos de populações de arroz (Oryza sativa L.) irrigado por inundação em função de épocas de cultivo. 1994. Tese (Livre Docência) - Faculdade de Ciências Agronômicas. Universidade Estadual Paulista, Botucatu.

MAIA, C. E.; MORAIS, E. R. C.; OLIVEIRA, M. Classificação da composição iônica da água de irrigação usando regressão linear múltipla. Revista Brasileira de Engenharia Agrícola e Ambiental, Campina Grande, v. 5, n. 1, p. 55-59, 2001.

MARCHEZAN, E.; MARTIN, T. N.; SANTOS, F. M.; CAMARGO, E. R. Análise de coeficiente de trilha para os componentes de produção em arroz. Ciência Rural, Santa Maria, v. 35, n. 5, p. 1027-1033, 2005.

MEDEIROS, R. D.; SOARES, A. A.; GUIMARÃES, R. M. Compactação do solo e manejo da água. I: efeitos sobre a absorção de N, P, K, massa seca de raízes e parte aérea de plantas de arroz. Ciência e Agrotecnologia, Lavras, v. 29, n. 5, p. 940-947, 2005.

MEIRA, F. A.; BUZETTI, S.; FREITAS, J. G.; ARF, O.; SÁ, M. E. Resposta de dois cultivares de arroz à adubação nitrogenada e tratamento foliar com fungicidas. Acta Scientiarum. Agronomy, Maringá, v. 27, n. 1, p. 91-95, 2005.

MOLIN, J. P.; VIEIRA JUNIOR, P. A.; DOURADO NETO, D.; FAULIN, G. C.; MASCARIN, L. Variação espacial na produtividade de milho safrinha devido aos macronutrientes e à população de plantas. Revista Brasileira de Milho e Sorgo, Sete Lagoas, v. 6, n. 3, p. 309-324, 2007.

MOURA NETO, F. P.; SOARES, A. A.; AIDAR, H. Desempenho de cultivares de arroz de terras altas sob plantio direto e convencional. Ciência e Agrotecnologia, Lavras, v. 26, n. 5, p. 904-910, 2002.

SCHLOTZHAVER, S. D.; LITTELL, R. C. SAS system for elementary statical analysis. 2. ed. Cary: SAS, 1997. $441 \mathrm{p}$.

SHAPIRO, S. S.; WILK, M. B. An analysys of variance test for normality: complete samples. Biometrika, London, v. 52, n. 3-4, p. 591-611, 1965.

SILVA, E. A.; SORATTO, R. P.; ADRIANO, E.; BISCARO, G. A. Avaliação de cultivares de arroz de terras altas sob condições de sequeiro em Cassilândia, MS. Ciência e Agrotecnologia, Lavras, v. 33, n. 1, p. 298304, 2009.

SILVA, E. A.; SORATTO, R. P.; OZEKI, M.; ARF, O. Manejo da época de aplicação da adubação potássica em arroz de terras altas irrigado por aspersão em solo de cerrado. Acta Scientiarum: Agronomy, Maringá, v. 24, n. 5, p. 1455-1460, 2002. 
SILVA, M. R. M. Periodos de interferência das plantas daninhas na cultura do arroz de terras altas. 2006. Tese (Doutorado em Agronomia) - Faculdade de Ciências Agrárias e Veterinárias. Universidade Estadual Paulista, Jaboticabal.

YOSHIDA, S. Climatic environmentand its influence. In: . Fundamentals of rice crop science. Los Baños: International Rice Research Institute, 1981a. cap. 2, p. $65-110$.

. Growth and development of the rice plant. In: . Fundamentals of rice crop science. Los Baños: International Rice Research Institute, 1981b. cap. 1, p. $1-65$.
ZAFFARONI, E.; TERRES, A. L.; BEVILAQUA, G. A. P.; ROBAINA, A. D.; LIMA, D.; SILVA FILHO, P. M.; LOPES, R. Análise de caminho nos componentes do rendimento de genótipos de arroz no Rio Grande do Sul. Pesquisa Agropecuária Brasileira, Brasília, v. 33, n. 1, p. 43-48, 1998.

ZARATIN, C.; SOUZA, S. A.; PANTANO, A. C.; SÁ, M. E.; ARF, O.; BUZETTI, S. Efeitos de quatro doses de potássio em seis cultivares de arroz de sequeiro irrigados por aspersão. I. Componentes de produção e produtividade. Científica, Jaboticabal, v. 32, n. 2, p. 115120, 2004. 
